\title{
UPON THE NUMERICAL SIMULATION OF THE FOAM MATERIALS BEHAVIOR USING ELEMENT FREE GALERKIN METHOD
}

\author{
NASTASESCU Vasile \\ Prof. Eng. Ph.D., Military Technical Academy, Bucharest, Romania, nastasescuv@gmail.com \\ BARSAN Ghita \\ Prof. Eng. Ph.D., Land Forces Academy, Sibiu, Romania, ghbarsan@gmail.com \\ MOCIAN Oana \\ Teaching assistant Eng., Ph.D. student, Military Technical Academy, Bucharest, Romania, \\ mocian.oana@gmail.com
}

\begin{abstract}
The foam materials, by construction and by characteristic properties (low density, large deformations, great flexibility, Poisson ratio practically zero etc.), are widely used in many and various domains. The numerical simulation of the foam material behavior raises some difficulties, which can be impassable under certain circumstances. This paper presents some of our researching results in numerical modeling of foam materials, which can be very useful for those interested in numerical modeling of the foam materials. Numerical modeling used by the authors is based on the finite element method (FEM) and on the element-free Galerkin (EFG) method. The results are presented in a comparatively way and they also present how some usually running errors can be avoided. The conclusions and the results are considered by the authors very useful in modeling of the foam materials and in choosing of the most fitted method too.
\end{abstract}

Key words: Foam Materials, FEM, EFG, Contact, Material Model

\section{Introduction}

The foam materials represent a special kind of materials which are used more and more in many fields (industry, transport, innovation etc.) owing to their properties and their behavior (specially under dynamic loads). The properties and the behavior of the foam materials come from their construction, being materials with a spongelike, cellular structure. This material structure makes them with a high deformation rate, very flexible, with a large energy absorption capacity and with a low density. Of course, such materials have lower elastic characteristics comparatively with others materials, but the Poisson ratio practically goes to zero. All these aspects make the numerical simulation of such materials behaviour a difficult task.

Some one could say that the foam materials have a similar behaviour with hyperelastic materials; the comparison of the foam materials with the hyperelastic materials can be made and it can be true, only the mathematical formulation is concerned, otherwise there are essential differences. For hyperelastic materials, the main working conditions consist in tension and Poisson's ratio is near 0.50, while for foam materials the main working conditions consist in compression and Poisson's ratio is near zero. The tests for these materials can be similar and the methodology also, but for the foam materials, the compression test is the main test Owing to the large deformations, the numerical calculus is a nonlinear one, including the both nonlinearities: material and geometric nonlinearities.

Starting from these aspects, special material models were designed. About using of these material models, about using of different numerical methods, someone can find information which can be useful in solving of similar problems.

2. Mathematical Approaching Fundamentals of Foam Materials

Starting from the observation that foam materials have Poisson's ratio value about zero 
(practically $v=0$ ), knowing that the volume strain $e$ of the specimen, in the case of monoaxial stress state, has the definition relation,

$e=\frac{\Delta V}{V_{0}}=(1-2 v) \varepsilon$

where $\Delta V=V-V_{0}$ is the volume variation, $V$ is the volume at a testing time, $V_{0}$ is the initial volume, $v$ is the Poisson's ratio and $\varepsilon$ is the strain on the testing direction, we can see the link between physical behavior and the value of Poisson's ratio; hyperelastic materials are practically incompressible, so $\Delta V=0$, but the relation (1) shows that this is possible only if $v=0.5$; foam materials have a large deformation when volume strain $e$ goes near to 1.0 ; in these conditions the relation (1) shows that the Poisson's ratio has to go to zero value and numerically, $e=\varepsilon$.

The general mathematical method for the studing of the strains, stresses, displacements and other parameters, consist in finding of a strain energy function, which then, by mathematical operations, allows the calculation of the desired parameter. All these functions and parameters are expressed in terms of the principal stretches $\lambda_{1}, \lambda_{2}, \lambda_{3}$ which are defined like in the Figure 1.
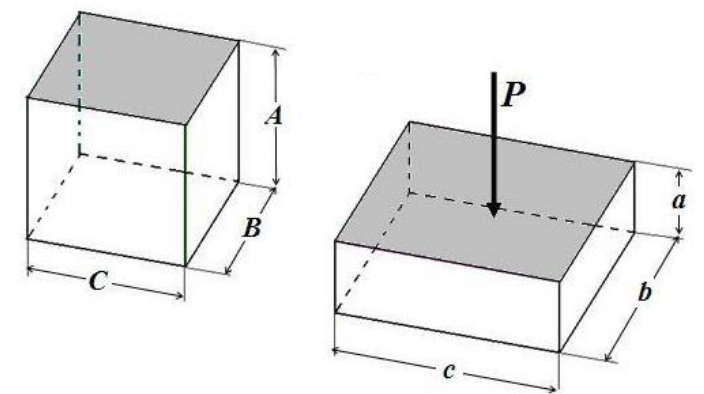

Figure 1: Uniaxial test of compression

The principal stretch ratios $\left(\lambda_{i}\right)$ are defined according to the relation (2). Both in stretching and compression, these parameters $\lambda_{i}$ have only positive values, the maximum value being 1.0.

$\left\{\begin{array}{l}\lambda_{1}=\frac{a}{A} \\ \lambda_{2}=\frac{b}{B} \\ \lambda_{3}=\frac{c}{C}\end{array}\right.$

By testing, the dependence between compression force and stretch ratio can be obtained; the allure and commune values, for a polymeric foam, can be seen in the Figure 2. How the stresses depend on the strains, in a uniaxial compression test of a polymeric foam, can be watched in the Figure 3.

By an uniaxial test (Figure 1), the principal true stress $\sigma$ can be written in terms of principal engineering stress $\left(\sigma^{E}\right)$ and principal stretches $\left(\lambda_{i}\right)$ :

$$
\begin{aligned}
& \sigma(\lambda)=\frac{P}{b \cdot c}=\frac{P}{\lambda_{2} \lambda_{3} \cdot B \cdot C}=\frac{P}{\lambda_{2} \lambda_{3} \cdot A_{0}}=\frac{\sigma^{E}}{\lambda_{2} \lambda_{3}} \\
& \sigma(\lambda)=\sigma^{E} \cdot \lambda_{2}^{-1} \cdot \lambda_{3}^{-1}
\end{aligned}
$$

The strains can also be expressed in terms of principal stretches; for the principal direction 1: 
ACTA UIVERSITATIS CIBINIENSIS - TECHNICAL SERIES

Vol. LXIX 2017

$\lambda_{1}=\frac{a}{A}=\frac{\left(1+\varepsilon_{1}\right) A}{A}=1+\varepsilon_{1}$

From relation (5), by generalization, relation (6) can be written:

$\varepsilon_{i}=\lambda_{i}-1$

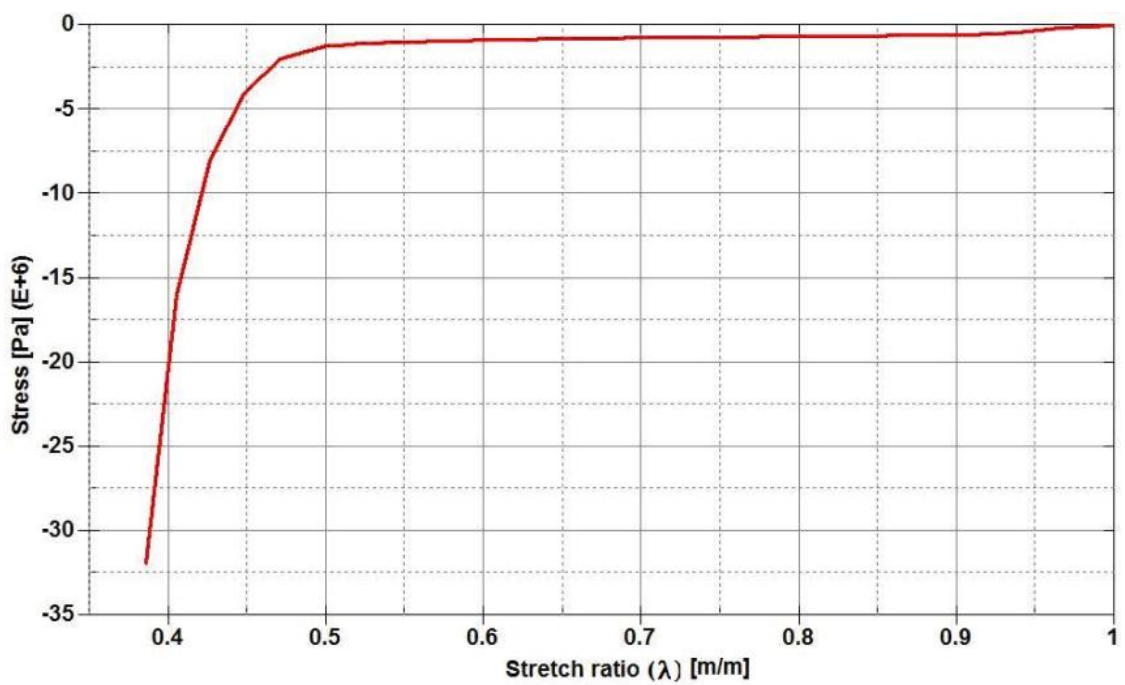

Figure 2: Stress versus stretch ratio, for a compression test

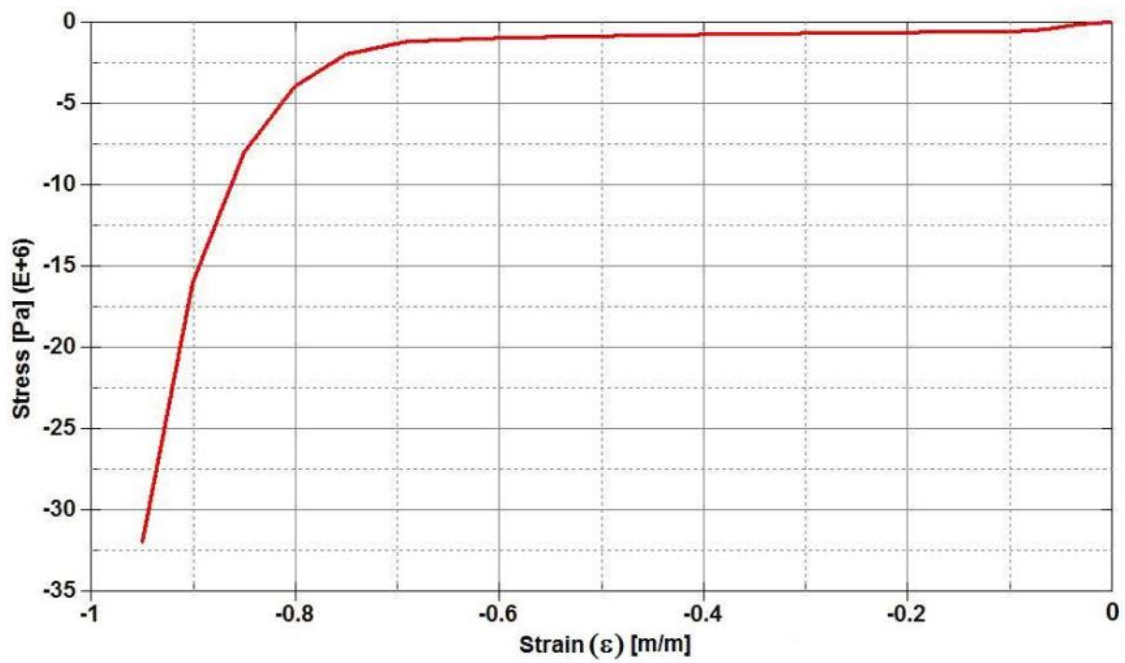

Figure 3: Stress versus strain, for a compression test

The expression (6) is named in literature Biot strain or co-rotated engineering strain. In nonlinear analysis, with material nonlinearities and large deformations, others used strain measures are also used, as functions of principal stretch rations, like Green strain, Almansi strain and log (true) strain, as the relations (7) to (9), respectively, shows.

$\varepsilon_{i}=\frac{1}{2}\left(\lambda_{i}^{2}-1\right)$

$\varepsilon_{i}=\frac{1}{2}\left(1-\frac{1}{\lambda_{i}^{2}}\right)$

$\varepsilon_{i}=\ln \lambda_{i}$ 
The use of principal stretch rations $\left(\lambda_{1}, \lambda_{2}, \lambda_{3}\right)$ is preferred because these are invariant with respect to both the coordinate system and the strain measure. So, as it can be seen $\varepsilon=f(\lambda)$ and $\varepsilon$ has to increase monotonically with $\lambda$, for to be valid for mathematical operations (Taylor serie development etc.) By above reasons, a strain energy function $(\varphi)$ is also expressed in terms of $\lambda_{1}, \lambda_{2}, \lambda_{3}$.

Such an energy function, $\varphi(\lambda)$, would have to full fill some conditions, by mathematical and physical reasons:

- $\quad$ to be zero for a ground state, when $\lambda_{1}=\lambda_{2}=\lambda_{3}=1$;

- $\quad$ to be symmetric in $\lambda_{i}$;

- $\quad$ to be always greater or equal then zero, $\lambda(\varphi) \geq 0$;

- to be a convex function.

The energy function has to be a convex one, for stability reason, so any change in deformation field will produce an unique change in the stress field. Let's consider the energy function $\varphi(\lambda)=\varphi\left(\lambda_{1}, \lambda_{2}, \lambda_{3}\right) ;$ the variation of this function, with respect to $\lambda_{i}$ can be written:

$d \varphi(\lambda)=\frac{\partial \varphi}{\partial \lambda_{1}} d \lambda_{1}+\frac{\partial \varphi}{\partial \lambda_{2}} d \lambda_{2}+\frac{\partial \varphi}{\partial \lambda_{3}} d \lambda_{3}$

The specific behaviour of the foam material is reflected by the stress-strain relationship. Such a typical curve is presented in the Figure 4. Three zones are noticed in the compressive stress-strain relationship of a foam material: Zone 1 is an initial region where the behavior is linear elastic, then Zone 2 is represented by a flat plateau (like an yielding zone) and Zone 3 (densification zone) when relation between stress and strain is an exponential one.

In the first zone, foams have some stiffness due to the strength of the matrix material itself. The curve is fairly linear and the stretch ratio of $\lambda$ has the value range from 0.95 to 1 . This zone is called the initial stiffness of the foam. The yielding plateau (Zone 2) is the result of the gaseous component in foam structure. The gas exits the foam through the open pores or channels. In closed cell foams, the gas is compressed. The stresses remain at about the same level, until $\lambda$ reaches a value of $0.4-0.5$, when by bending the cell walls collapse and a new zone appears. The Zone 3 (densification phenomenon) begins when the gas pressure is high enough to rupture the cell wall thereby releasing the gas to the atmosphere.

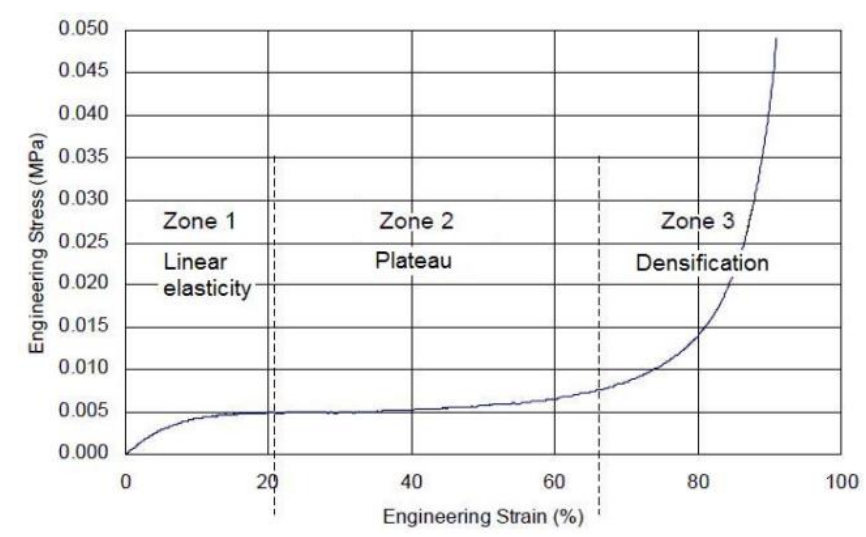

Figure 4: A typical strain-stress curve of a material foam 


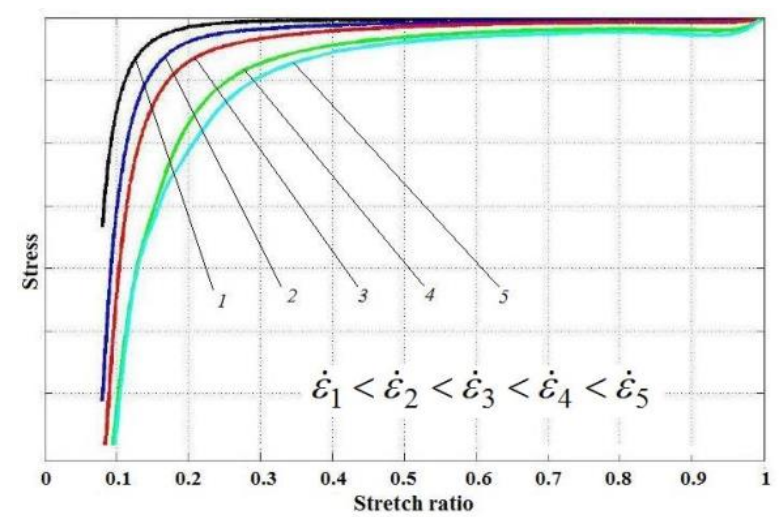

Figure 5: The influence of the strain rate upon stress-stretch ratio

It is very important that the stress-strain curve to cover the strain range occurring in reality; otherwise, some characteristic errors can appear and the numerical simulation will be stoped. In these cases, some possibilities for avoiding such problems exist and these will be presented in this paper later.

Like many others materials, the foam materials are also sensitive to the strain rate $\dot{\varepsilon}=\frac{d \varepsilon}{d t}$. By an uniaxial compressive test, at different strain rates, the stress-stretch ratio curves have allures presented in the Figure 5. Because of material nonlinearities and because of large deformations, nodal stresses and displacements are very difficult to be calculated by "classical" way of the finite element analysis. By this reason, such parameters are calculated starting from the energy function, $\varphi(\lambda)$ and using some stress measures, next to Cauchy stress tensor; so, first and second Piola-Kirchhoff stress tensor, Jaumann stress tensor and others tensors or connection matrixes are used.

\section{Material Models}

Because of special properties of the foam materials (a part of them synthetically presented above), many professional numerical analysis programs offer some foam material models These material models have the same fundamentals which, in a synthetic way, will be presented below.

For all foam material models, the main theoretical issue is the energy functional $\varphi(\lambda)$. So, Hill's energy functional (one of the most used) is:

$$
\varphi(\lambda)=\sum_{m=1}^{k} \frac{\mu_{m}}{\alpha_{m}}\left(\lambda_{1}^{\alpha_{m}}+\lambda_{2}^{\alpha_{m}}+\lambda_{3}^{\alpha_{m}}-3+\frac{1}{n}\left(J^{-\alpha_{m} n}-1\right)\right)
$$

where $k$ is the number of terms in the function, $n, \alpha_{m}$ and $\mu_{m}$ are material constants, $\lambda_{1}, \lambda_{2}, \lambda_{3}$ are the principal stretches or the stretch ratio in the corresponding principal direction 1,2, 3 and $J$ is the relative volume (Figure 1):

$$
J=\frac{V}{V_{0}}=\frac{a \cdot b \cdot c}{A \cdot B \cdot C}=\lambda_{1} \cdot \lambda_{2} \cdot \lambda_{3}
$$

The principal Kirchhoff stress components can be determined [3] by the following relation coming from relation (11):

$$
\tau_{i i}^{K}=\lambda_{i} \frac{\partial \varphi}{\partial \lambda_{i}}=\sum_{m=1}^{k} \frac{\mu_{m}}{J}\left(\lambda_{i}^{\alpha_{m}}-J^{-n \alpha_{m}}\right)
$$

The Cauchy stress components $\left(\sigma_{i j}\right)$ are then obtained:

$$
\sigma_{i j}=J^{-1} \cdot \tau_{i j}
$$

where $\tau_{i j}$ are the components of the standard Kirchhoff stresses obtained by the formula [2]: 


$$
\tau_{i j}=q_{i k} \cdot q_{j l} \cdot \tau_{k l}^{K}
$$

The components $q_{i j}$ are the elements of the orthogonal tensor containing the eigenvectors of the principal basis (coordinates corresponding with the principal stresses). Many other details are given in documentation of the used program. In the material library of the Ls-Dyna program, some material models for foam materials exist: Low Density Urethane Foam, MAT_FU_CHANG_FOAM, MAT_HILL_FOAM, MAT_VISCOELASTIC_HILL_FOAM and Simplified Rubber/Foam. A special attention has to be paid to the selecting of the material model; the material properties have to be known but in the same time the goal of using of foam material has to be analyzed.

\section{Used Numerical Methods}

An impact problem in which the target is of foam materials can by easily studied using numerical methods. First of all, we all are thinking to the Finite Element Method (FEM).

This method is well known and large used in the world and in our country too. Nowadays, this method don't is a single one. Among the numerical methods, which appeared, which have been developed and which have been implemented in the most powerful professional programs, the Element Free Galerkin (EFG) method is one of them. This numerical method belongs to a large category of numerical methods, named mesh free methods. Unfortunately, in our country these numerical methods are few known and fewer used. Some theoretical fundamentals regarding Element Free Galerkin (EFG) method is presented below, because the FEM fundamentals are generally well known.

\subsection{Fundamentals of the Element Free Galerkin Method}

The weighted residual method is a general method for obtaining approximate solutions for ordinary differential equations (ODEs) or partial differential equations (PDEs). Many numerical methods like collocation method, subdomain method, least squares method, moment method and Galerkin method are based on the general weighted residual method.

The Element Free Galerkin (EFG) method is based on Galerkin method with Moving Least Squares (MLS) interpolants. The approximation by MLS was devised by mathematicians: Lancaster and Salkausdas 1981 and others [1], [7]. This method is categorized as a method of series representation of functions and it is widely used in mesh free methods.

Let's consider an unknown scalar function of a field variable $u(x)$, in a domain $\Omega$. The moving least squares approximation $u^{h}(x)$, of the variable $u(x)$, is defined so:

$$
u^{h}(x)=\sum_{j=1}^{m} p_{j}(x) \cdot a_{j}(x)
$$

or, in a matrix form,

$$
u^{h}(x)=p^{T}(x) \cdot a(x)
$$

where $p(x)$ is the basis function (a complete one) of the spatial coordinates and $m$ is the number of the basis functions. In the relation (18), $a(x)$ is a vector of coefficients, which can be written so:

$$
a^{T}(x)=\left[\begin{array}{lllll}
a_{1}(x) & a_{2}(x) & \ldots & \ldots & a_{m}(x)
\end{array}\right]
$$

The components (elements) of the vector $a(x)$ are functions of $x$. These components (polynomial coefficients) can be determined by minimizing the following functional $(J)$

$$
J=\sum_{i=1}^{n} \widehat{W}\left(x-x_{i}\right)\left[p^{T}\left(x_{i}\right) \cdot a(x)-u_{i}\right]^{2}
$$

where $n$ is the number of nodes, in the support domain of $x$, for which the weight function $\widehat{W}\left(x-x_{i}\right) \neq 0$, and $u_{i}$ is the nodal parameter of $u$, at $x=x_{i}$.

The minimizing of the functional $(J)$, requires: 
ACTA UIVERSITATIS CIBINIENSIS - TECHNICAL SERIES

Vol. LXIX 2017

$$
\frac{\partial J}{\partial a}=0
$$

so, the following set of linear matrix relations are obtained:

$A(x) \cdot a(x)=B(x) \cdot U_{s}$

where $U_{s}$ is the vector of nodal field function parameters, for all nodes in the support domain, $A(x)$ is the weighted moment matrix and $B(x)$ is a matrix resulting from relation (26). All these matrixes are written so:

$$
\begin{aligned}
& U_{s}=\left[\begin{array}{llll}
u_{1} & u_{2} & \ldots . . & u_{n}
\end{array}\right]^{T} \\
& A(x)=\sum_{i=1}^{n} \widehat{W}_{i}(x) \cdot p\left(x_{i}\right) \cdot p^{T}\left(x_{i}\right) \\
& B(x)=\left[\begin{array}{llll}
\widehat{W}_{1}(x) \cdot p\left(x_{1}\right) & \widehat{W}_{2}(x) \cdot p\left(x_{2}\right) & \ldots . . & \widehat{W}_{n}(x) \cdot p\left(x_{n}\right)
\end{array}\right]
\end{aligned}
$$

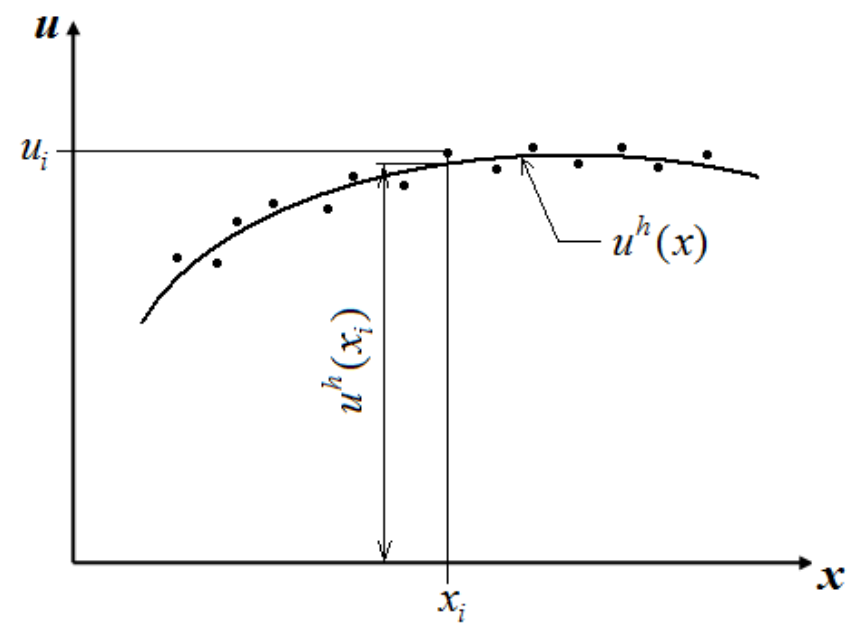

Figure 6: The approximation function and the nodal parameters, in MLS method

Usually, the number of nodes $n$, used in MLS method, is much larger than the number of unknown coefficients $m$, the approximation function $u^{h}(x)$ does not pass through the nodal values, like in the Figure 6. By solving the matrix equation (26), the vector of coefficients $a(x)$ is obtained:

$a(x)=A^{-1}(x) \cdot B(x) \cdot U_{s}$

Substituting the relation (30) into relation (17), we write:

$u^{h}(x)=\sum_{i=1}^{n} \phi_{i}(x) \cdot u_{i}=\Phi^{T}(x) \cdot U_{s}$

where $\Phi(x)$ is the vector of shape functions, corresponding to the $n$ nodes of the support domain of the point $x$ :

$$
\Phi^{T}(x)=\left[\begin{array}{llll}
\phi_{1}(x) & \phi_{2}(x) & \ldots . & \phi_{n}(x)
\end{array}\right]
$$

The shape functions $\phi_{i}(x)$, for $i^{\text {th }}$ node can be written in a discrete form or in a matrix form, as the relation (33) shows.

$$
\phi_{i}(x)=\sum_{j=1}^{m} p_{j}(x) \cdot\left(A^{-1}(x) \cdot B(x)\right)_{j i}=p^{T}(x) \cdot\left(A^{-1} \cdot B\right)_{i}
$$

As we can see analyzing the above relations, in the MLS method the coefficients $a$ are functions of $x$, by which the approximation move continuously. A properly choosen of the shape function makes 
ACTA UIVERSITATIS CIBINIENSIS - TECHNICAL SERIES

Vol. LXIX

2017

this to be continue in the entire global domain $\Omega$.

As the Ls-Dyna program is concerned, a cubic B-spline weight function is used.

\section{Numerical Examples}

Consider a foam plane plate with a diameter of $60 \mathrm{~mm}$ and its thickness of $25 \mathrm{~mm}$, being fixed on a rigid surface. This circle foam plate is impacted by a sphere with a diameter of $40 \mathrm{~mm}$ and a weight of 5 $\mathrm{kg}$ having an impact velocity of $5 \mathrm{~m} / \mathrm{s}$.

The paper presents the numerical results obtained by two methods: FEM and Element-Free Galerkin method, for an analysis time of 0.003 seconds.

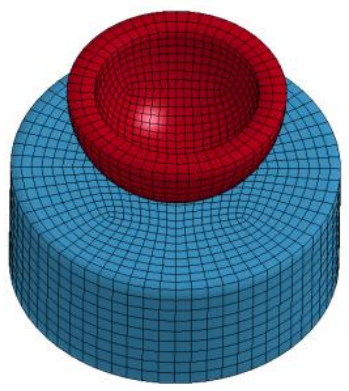

a)

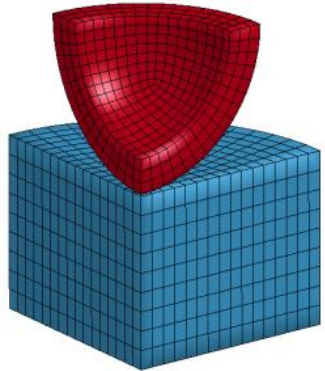

b)

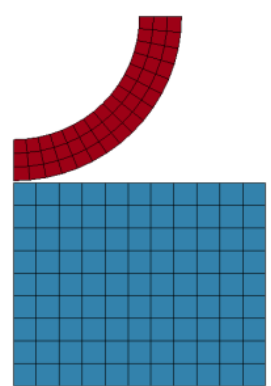

c)

Figure 7: Models for analysis by FEM and EFG method

In the Figure 7, three models with finite elements are presented: a) a 3D model, b) a quarter of a 3D model and c) a 2D axisymetric model. The same models are used for the EFG method.

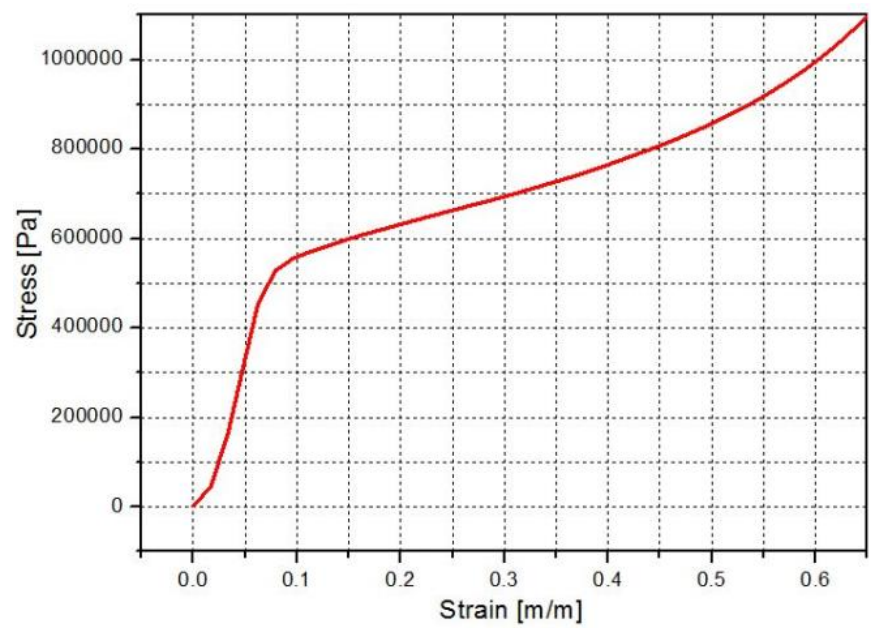

Figure 8: The initial stress-strain curve of the foam material

By the reason of computer time, the sphere was partial modeled, but using a special procedures of the program, the impact mass was the same weight $(5 \mathrm{~kg})$.

The constitutive law of the foam is graphically presented in the Figure 8. All the results presented below are obtained by using the Ls-Dyna program.

The great discrepancy between the rigidity of the foam and the impactor makes the contact not to work, appearing the errors "negative volume" \& "complex sound speed" and running stops.

Using the Ls-Dyna program, this inconvenience could be overpassed by two ways: by extending the curve stress-strain of the foam material, or giving a positive value (around 1.0\% of impactor Young modulus) to the parameter KCON (of material model) and using the option SOFT=1 (contact formulation) 
ACTA UIVERSITATIS CIBINIENSIS - TECHNICAL SERIES

Vol. LXIX 2017

Table 1: Running Results for 3D FE Modeling

\begin{tabular}{|c||c||c|c||c|c||c|c|c|}
\hline $\begin{array}{c}\text { Test } \\
\text { No. }\end{array}$ & $\begin{array}{c}\text { Initial } \\
\text { curve }\end{array}$ & $\begin{array}{c}\text { SOFT } \\
\mathbf{0}\end{array}$ & $\begin{array}{c}\text { SOFT } \\
\mathbf{1}\end{array}$ & $\begin{array}{c}\text { KCON } \\
\mathbf{0}\end{array}$ & $\begin{array}{c}\text { KCON } \\
\mathbf{2 0 0 0}\end{array}$ & $\begin{array}{c}\text { HGID } \\
\mathbf{0}\end{array}$ & $\begin{array}{c}\text { HGID } \\
\mathbf{1}\end{array}$ & Effects \\
\hline $\mathbf{1}$ & YES & YES & --- & YES & --- & YES & -- & Error \\
\hline $\mathbf{2}$ & YES & YES & --- & YES & --- & --- & YES & Error \\
\hline
\end{tabular}

Our researching lead to the conclusion that taking into account of the hourglass energy is not important, having a less value towards the kinetic or internal energy. Its influence is a little one. Then, the hourglass energy cannot be taken into account when EFG method or any mesh free method is used.

The results obtained by using $3 \mathrm{~d}$ models with FE and EFG are synthetically presented in the below tables. These results, presented in Table 1 and in Table 2, show us that using the EFG method makes those errors to be avoided and the quantitative values to be in according to the reality.

Table 2: Running Results for 3D EFG Modeling

\begin{tabular}{|c||c|c|c||c|c||c|c||c|}
\hline No. & $\begin{array}{c}\text { Initial } \\
\text { curve }\end{array}$ & $\begin{array}{c}\text { SOFT } \\
\mathbf{0}\end{array}$ & $\begin{array}{c}\text { SOFT } \\
\mathbf{1}\end{array}$ & $\begin{array}{c}\text { KCON } \\
\mathbf{0}\end{array}$ & $\begin{array}{c}\text { KCON } \\
\mathbf{2 0 0 0}\end{array}$ & $\begin{array}{c}\text { HGID } \\
\mathbf{0}\end{array}$ & $\begin{array}{c}\text { HGID } \\
\mathbf{1}\end{array}$ & Effects \\
\hline $\mathbf{1}$ & YES & YES & --- & YES & --- & YES & -- & O.K. \\
\hline $\mathbf{2}$ & YES & YES & --- & YES & --- & --- & YES & O.K. \\
\hline
\end{tabular}

In the Figures 9, 10, 11, and 12, the time evolution of the kinetic energy, velocity, displacement and respectively the contact force of the impactor are presented, using FEM or EFG method.

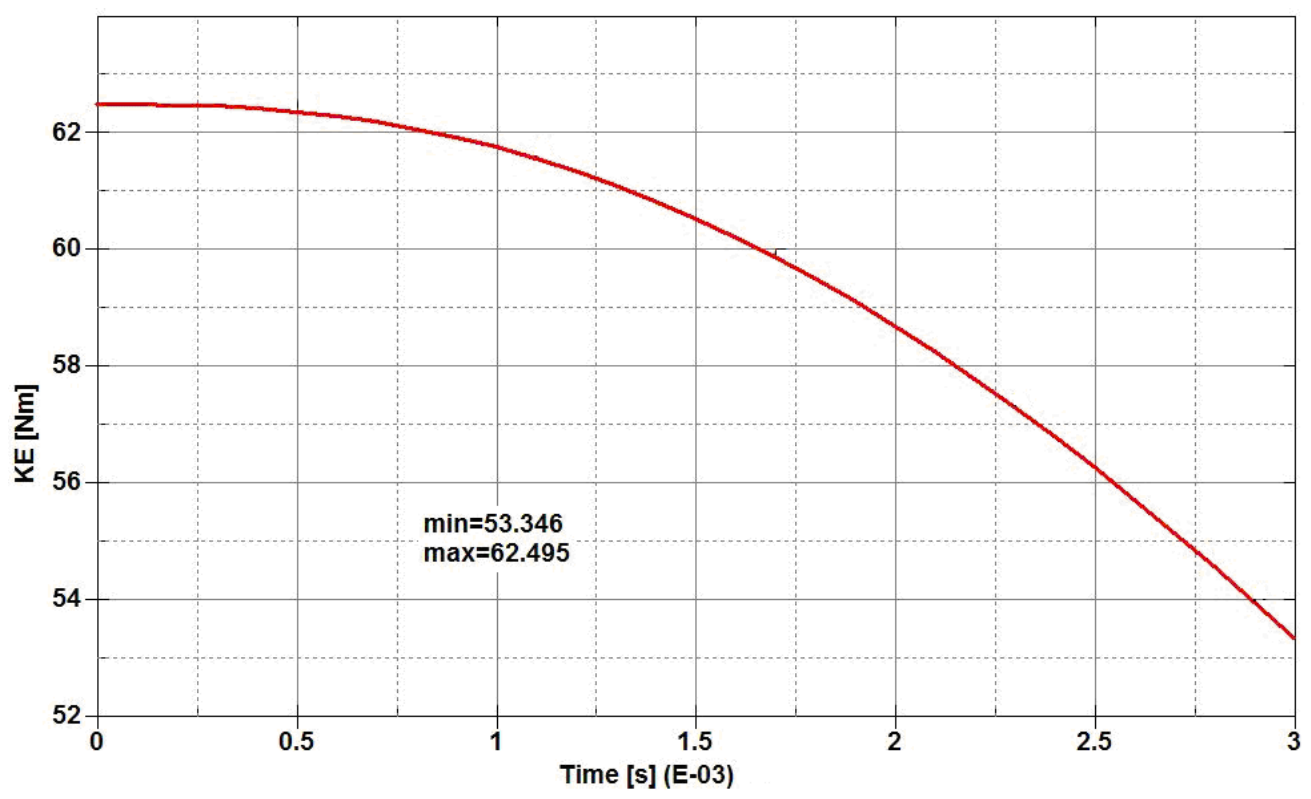

Figure 9: Time evolution of the impactor kinetic energy, by EFG method 
ACTA UIVERSITATIS CIBINIENSIS - TECHNICAL SERIES Vol. LXIX 2017

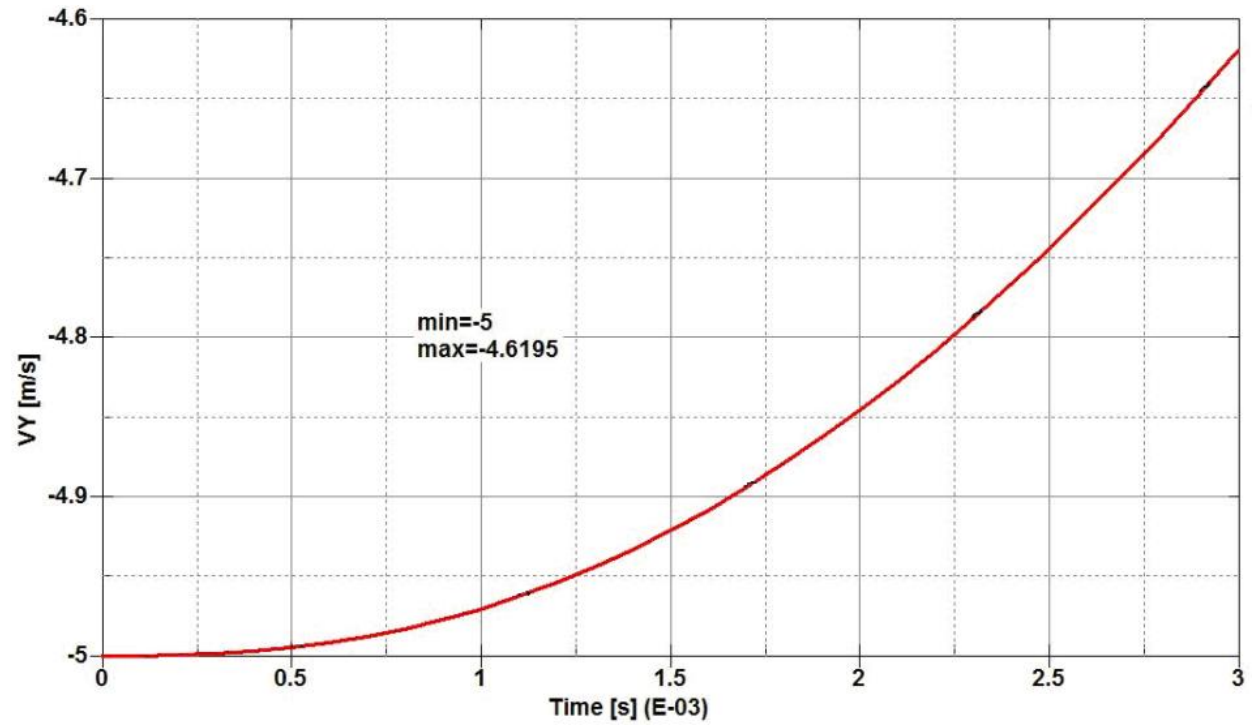

Figure 10: Time evolution of the impactor velocity, by EFG method

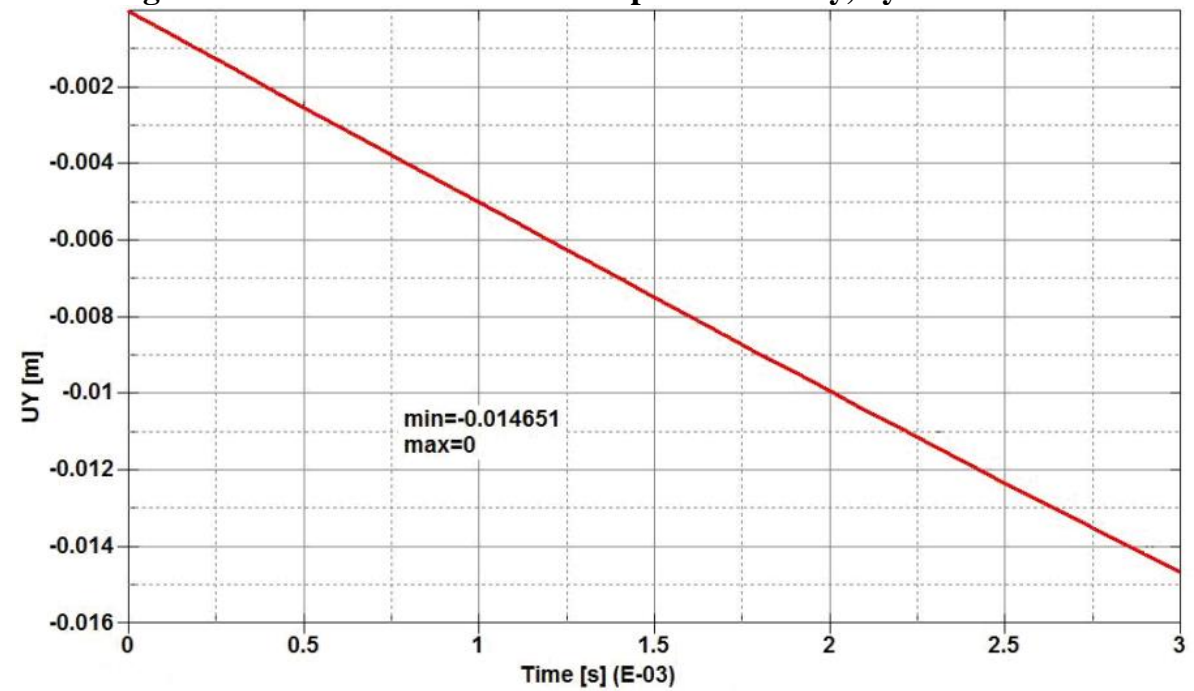

Figure 11: Time evolution of the impactor displacement, by EFG method

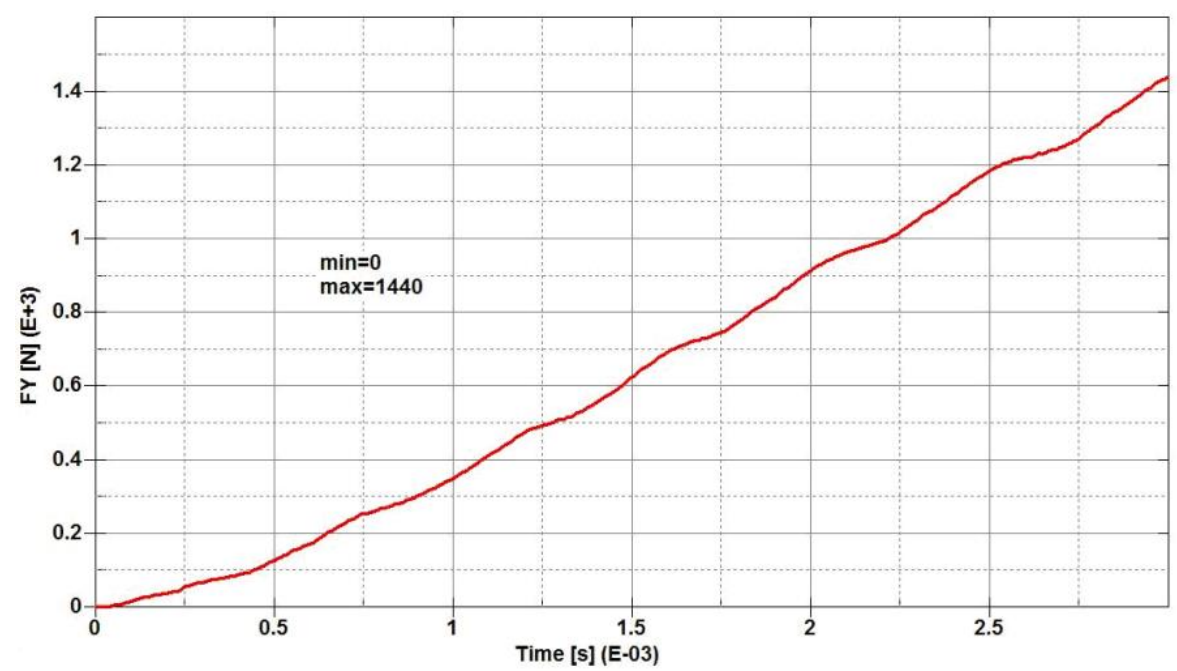

Figure 12: Contact force between impactor and foam plate, by FEM 
ACTA UIVERSITATIS CIBINIENSIS - TECHNICAL SERIES

Vol. LXIX 2017

Some deformed states, obtained with 3D and 2D modeling, by FEM and by EFG are presented in the Figure 13 (a-3D FEM, b-3D_1/4 EFG, c-2D EFG). Practically, no diferences exist.

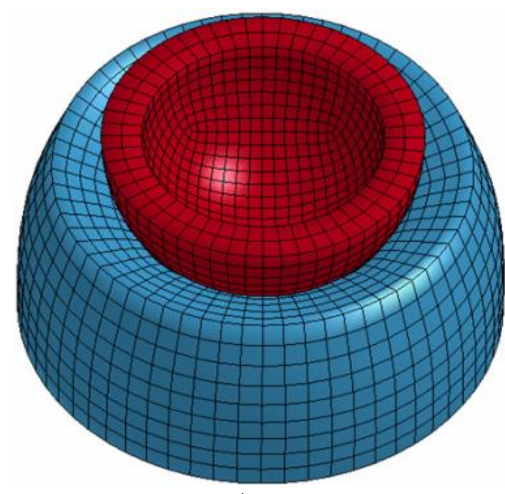

a)

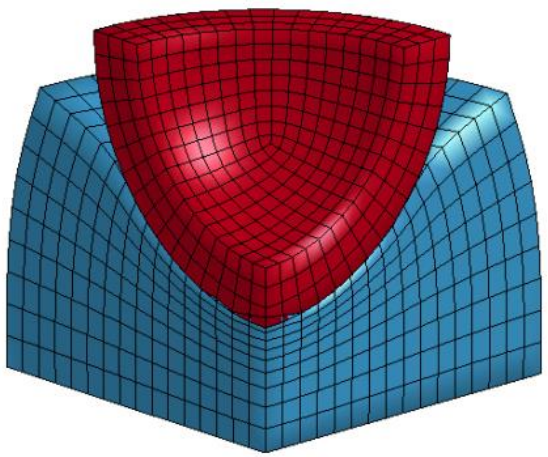

b)

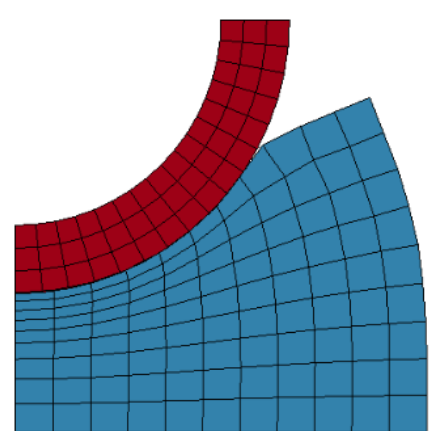

c)

Figure 13: Deformed state by FEM (a), by EFG (b) and by 2D EFG (c)

The Table 3 comparativelly presents the results obtained by modeling with FE, but using the initial curve (Figure 7) and the extended curve presented in the Figure 14. The difference between impactor displacements UY (Tests no. 3 and 4) represents the influence of the hourglass energy.

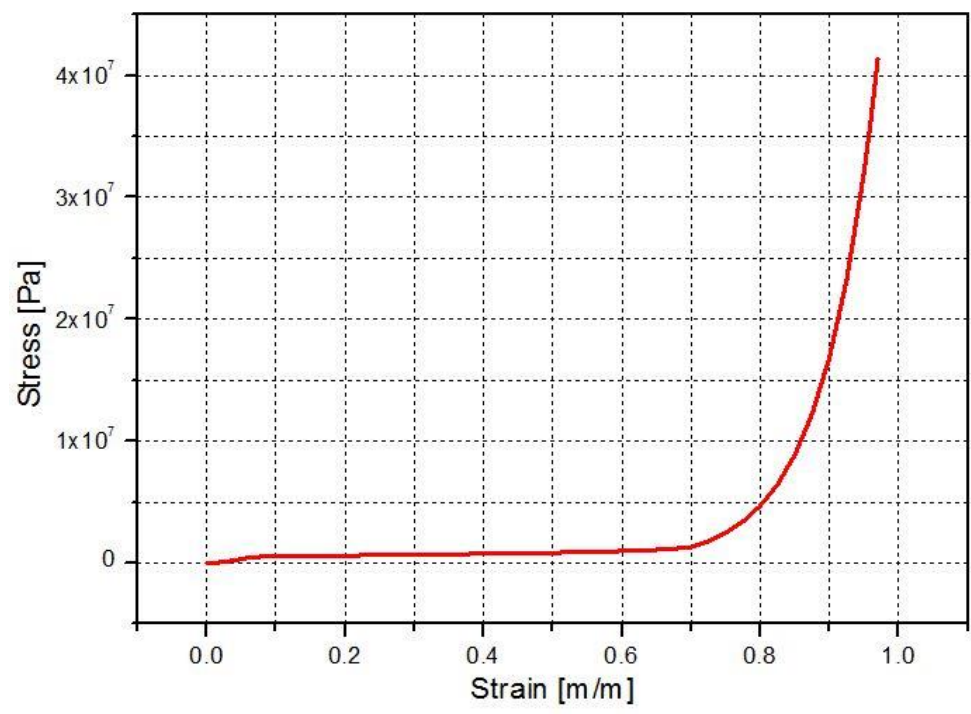

Figure 14: The extended constitutive foam curve

Table 3: Comparative Results for FE Analysis and Two Types of the Constitutive Curve

\begin{tabular}{|c||c|c||c|c||c|c||c|c||c|}
\hline $\begin{array}{c}\text { Test } \\
\text { No. }\end{array}$ & $\begin{array}{c}\text { Initial } \\
\text { curve }\end{array}$ & $\begin{array}{c}\text { Extended } \\
\text { curve }\end{array}$ & $\begin{array}{c}\text { SOFT } \\
\mathbf{0}\end{array}$ & $\begin{array}{c}\text { SOFT } \\
\mathbf{1}\end{array}$ & $\begin{array}{c}\text { KCON } \\
\mathbf{0}\end{array}$ & $\begin{array}{c}\text { KCON } \\
\mathbf{2 0 0 0}\end{array}$ & $\begin{array}{c}\text { HGID } \\
\mathbf{0}\end{array}$ & $\begin{array}{c}\text { HGID } \\
\mathbf{1}\end{array}$ & Effects \\
\hline \hline $\mathbf{1}$ & YES & --- & YES & --- & YES & -- & YES & --- & Error \\
\hline $\mathbf{2}$ & YES & --- & YES & --- & YES & --- & -- & YES & Error \\
\hline $\mathbf{3}$ & --- & YES & YES & --- & YES & --- & YES & --- & O.K... \\
\hline $\mathbf{4}$ & --- & YES & YES & --- & YES & --- & --- & YES & O.K.. \\
\hline
\end{tabular}


ACTA UIVERSITATIS CIBINIENSIS - TECHNICAL SERIES

Vol. LXIX 2017

Table 4: Obtained Results by 3D Modeling at $\mathbf{t}=\mathbf{0 . 0 0 3}$ seconds

\begin{tabular}{|c|c|c|c|c|}
\hline & \multicolumn{2}{|c|}{ FEM } & \multicolumn{2}{|c|}{ EFG Method } \\
\hline & $1 / 1$ & $1 / 4$ & $1 / 1$ & $1 / 4$ \\
\hline Kinetic Energy [J] & \multirow{2}{*}{53.213} & 52.704 & 53.346 & 53.312 \\
\hline Error [\%] & & -0.96 & 0.25 & \\
\hline Velocity [m/s] & \multirow{2}{*}{4.612} & 4.592 & 4.619 & 4.618 \\
\hline Error [\%] & & -0.43 & 0.15 & \\
\hline Displacement [mm] & \multirow{2}{*}{14.648} & 14.628 & 14.651 & 14.655 \\
\hline Error [\%] & & -0.14 & 0.02 & \\
\hline Contact Force $[\mathrm{N}]$ & \multirow{2}{*}{1440} & 1513 & 1343 & 1399 \\
\hline Error $[\%]$ & & 5.07 & -6.74 & -2.85 \\
\hline
\end{tabular}

As the Table 4 shows, the quantitative values of all numerical parameters, calculated by FEM and by EFG method are in a very good agreement.

Table 5: Obtained Results by 2D Axisymmetric Modeling at $\mathrm{t}=0.003$ seconds

\begin{tabular}{|c||c|c||c|}
\hline & 3D FEM & 2D FEM & 2D EFG Method \\
\hline \hline Displacement [mm] & \multirow{2}{*}{14.648} & 14.942 & 14.946 \\
\cline { 1 - 1 } Error $[\%]$ & & 2.01 & 2.03 \\
\hline Velocity $[\mathrm{m} / \mathrm{s}]$ & \multirow{2}{*}{4.612} & 4.936 & 4.9390 \\
\cline { 1 - 1 } & & 7.03 & 7.09 \\
\hline Error $[\%]$ & &
\end{tabular}

A similar study we made using a 2D axisymmetric model. As we can see in the Table 5, a good concordance between those two methods (FEM and EFG method) also exists, in the case of 2D axisymmetric modeling.

As the obtained results are concerned, these are much more than those presented in this paper. We selected only most important and most significant for the aim of our paper. Our research also included an analysis of the type and the finesse degree of the mesh. All the results referring to these aspects are those expected.

We are aware that not all the benefits of the EFG method have been demonstrated. The same as the foam behavior is concerned. All these will be the subjects of other papers.

\section{Conclusions}

This paper synthetically presents the fundamentals of the theoretical and numerical approaching of the foam materials. Some possibilities for over coming the errors appearing in numerical modeling of the contact between foam and rigid materials are also presented.

The paper presents the theoretical fundamentals of the EFG method. Also, the using of the EFG method is presented, for the same given problem. Three models were used in numerical modeling, by FEM and by EFG method: 3D full model, 3D a quarter model and 2D axisymmetric model. All the results are in a very good agreement.

The using of EFG method present some known advantages, specific to the meshless or free particle method, but also represent a viable way to overcome the errors that occur a given stress-strain curve of the foam materials. Of course, by post-processing of the results much more parameter would have been presented, about impactor and foam, but we have chosen only a few more useful parameters.

The paper can be useful to the researchers interested in numerical modeling of the foam materials. As the EFG method is concerned, this should have to be used in such circumstances and all 
ACTA UIVERSITATIS CIBINIENSIS - TECHNICAL SERIES

Vol. LXIX 2017

the time when large displacement and great nonlinearities occur.

\section{References}

1. Belytschko, T., Lu, Y. Y., Gu, L., Element-Free Galerkin Methods, International Journal for Numerical Methods in Engineering, Vol. 37, 229-256 (1994).

2. Brian Croop, Hubert Lobo, Selecting Material Models for the Simulation of Foams in LS-DYNA, $7^{\text {th }}$ European LS-DYNA Conference, 2009

3. Crisfield M. A., Non-linear Finite Element Analysis of Solids and Structures, John Wiley \& Sons, 1988, 2000, ISBN $047195649 \mathrm{X}$

4. Hallquist O. John, LS-DYNA Theory Manual, 1991-2006 Livermore Software Technology Corporation, ISBN 0-9778540-0-0

5. Liu, G. R., Meshfree Methods, Mooving Beyond the Finite Element Method, Second Edition, CRC Press Taylor \& Francis Group, 2010, LLC, ISBN 978-1-4200-8209-8

6. Liu, G. R., Liu, M. B., Smoothed Particle Hydrodynamics - a meshfree particle method, World Scientific Publishing Co. Pte. Ltd., ISBN 981-238-456-1.

7. Liu, G. R., GU, Y. T., An Introduction to Meshfree Methods and Their Programming, Published by Springer, P.O. Box 17, 3300 AA Dordrecht, The Netherlands, 2005, ISBN-10 1-4020-3228-5 (HB) Springer Dordrecht, Berlin, Heidelberg, New York.

8. Liu, M. B., Liu, G. R., Smoothed Particle Hydrodynamics (SPH): an Overview and Recent Developments, CIMNE, Barcelona, Spain 2010, Arch Comput Methods Eng (2010) 17: 25-76, DOI 10.1007/s11831-0109040-7

9. Năstăsescu, V., Bârsan, Gh., Metoda particulelor libere în analiza numerică a mediilor continue, Editura AGIR, Bucureşti, 2015, ISBN 978-973-720-617-6.

10. Năstăsescu V., Marzavan, S., Upon Impact Numerical Modeling of Foam Materials, Revista de MATERIALE PLASTICE, No.2/2017, pag. 195-202, ISSN 0025/5289

11. Năstăsescu V., Ştefan A., Lupoiu C., Analiza neliniară a structurilor mecanice prin metoda elementelor finite, Ed. Academiei Tehnice Militare, Bucureşti, 2002, ISBN: 973-8290-43-0

12. Oñate, E., Owen, R., Particle-Based Methods - Fundamentals and Applications, Springer Science+Business Media B.V., 2011, ISBN 978-94-007-0734-4, e-ISBN 978-94-007-0735-1

13. * * * LS-DYNA $^{\circledR}$ KEYWORD USER'S MANUAL, Vol. I, II, Livermore Software Technology Corporation (LSTC), 2014 